\title{
PELO OLHAR DA SEMIÓTICA: LEITURA E \\ PRODUÇÃO DE TEXTO
}

SIMÕES, Darcilia Marindir Pinto MELO, Eliana Meneses de

\section{INTRODUÇÃO}

Voltado para o amplo universo da linguagem, este artigo visa apresentar reflexões em torno dos diferentes olhares que as teorias da Semiótica e lingüísticas emprestam ao pesquisador cuja intencionalidade se direciona à análise e interpretação das produções discursivas engendradas pela sociedade. O mundo das práticas de vida é o mundo das linguagens, dos muitos discursos que percorrem as múltiplas ações e reações na vida cotidiana.

Livres e ao mesmo tempo presos nos constantes diálogos realizados em diferentes esferas da existência social, as linguagens são reveladoras de marcas culturais e das mudanças empreendidas no eixo da história. Mergulhada em mudanças originárias nos fatores tecnológicos e econômicos, esta sociedade tem em seu cerne a comunicação e o consumo a transitarem o cotidiano, ao mesmo que abarcam o homem: sujeito e objeto de um percurso que impõe e sobrepõe valores. São os efeitos das sociedades complexas, nas quais, em linhas irregulares, produzem e se fazem circular múltiplos discursos.

Nas dimensões da complexidade contemporânea encontra-se a uma gama enorme de percursos revestidos por signos em múltiplas significações. São as linguagens em criação e recriação a percorrerem os espaços do contraditório. É o verbo e as imagens que se associam em torno da metrópole em suas variadas formas de consumo cultural e entretenimento e que ao mesmo tempo em que integram diferentes sujeitos do corpo social, espelham as diferenças entre o imaginário e o lúdico a partir do espaço geográfico de residência e circulação. ( MELO: 2008, p. 8) 
Sendo os diferentes diálogos sociais dinâmicos, os enunciados que os materializam são igualmente dinâmicos e passam, no mínimo, por uma leitura para cada sujeito envolvido no ato de comunicação. Trata-se de leituras realizadas pelos sujeitos e de suas multiplicidades, como afirma Bakhtin (1988), ao tratar do aspecto responsivo do ouvinte. Qual seja, o sujeito que recebe o enunciado, ao compreendê-lo na prática do discurso, está em colóquio com as suas experiências. Neste sentido, é um sujeito plural que dialoga com o autor.

A capacidade e habilidades de leitura constituem elementos essenciais para o desenvolvimento do intelecto. Através das ações circunscritas à leitura, o sujeito realiza uma atividade de interpretação que Ihe leva a elaborar concordâncias ou refutações, incorporando, ou não, novas idéias em suas práticas cotidianas.

Por este entendimento, um dos pontos principais em torno do qual repousa a questão do entendimento e interpretabilidade se localiza na escrita, no registro efetivo das linguagens. Segundo TODOROV (1982), qualquer sistema semiótico visual espacial pode ser considerado um sistema de notação de linguagem: mitografia, logografia, morfemografia.

O homem tem registrado seus comunicados, suas intencionalidades discursivas através dos tempos, estabelecendo um diálogo entre um povo buscando ao outro: informa, comunica, tornam comum diferentes níveis de necessidades. Da sintaxe construída por imagens, representações de objetos, até chegar ao registro dos signos verbais, à semiótica complexa como hoje, a compreensão dessas sintaxes pressupõe o conhecimento do sujeito sobre a forma de representação utilizada, ou o desejo de entendê-las, de decifrá-las. (MELO: 2008. p.19)

Por certo que compreender enunciações, implica no reconhecimento das formas utilizadas para a comunicação, da cultura e dos valores que a gerou. A afirmação nos remete às práticas 
sociais, seus sistemas, sujeitos que apresentam diferentes níveis de experiências culturais e leitura de seu entorno, sempre gerando outros enunciados.

Haver humanos implica em existir discursos, sujeitos a produzirem discursos e leituras. Em tempos de diversidades tecnológicas, novos veículos de comunicação e maior precisão nos já existentes, tornam-se mais perceptíveis às complexidades sociais: dos indivíduos e dos discursos por eles produzidos. Sendo assim, a leitura vai além da apreensão maquinal de sentidos, deve atingir ao entendimento das situações humanas e gerar novas leituras.

De certa forma, pode-se compreender a leitura enquanto atividade social: lê-se o que está escrito, seja qual for o sistema representação. Reside na vida em comum a necessidade da leitura: ler o que é comunicado. Lê-se a fala dos sujeitos-leitores dos diferentes cenários: ler as linguagens em circulação, dentro das possibilidades que envolvem as próprias experiências humanas. Toda comunicação para ser apreendida, portanto, para ser lida, passa por um saber específico em relação à modalidade da linguagem na qual se manifeste o objeto da leitura. Assim, o nível de conhecimento incide no nível de apreensão realizado pelo sujeito.

Em síntese, no contexto onde as linguagens circulam, desenvolvem-se as transformações, traços de sentidos adicionados aos já existentes constroem, nas dinâmicas das linguagens em movimento, novos recortes e valores: cultura em movimento. Os sistemas conceituais fornecidos pela Semiótica emprestam a este artigo caminhos possíveis para reflexões sobre pesquisa, ensino e práticas de leitura.

\section{1-A LEITURA EM PERSPECTIVA ICÔNICA}

Em primeiro plano, a capacidade e habilidade de leitura são condições fundamentais para o desenvolvimento do intelecto. Pela 
convivência com textos, os sujeitos ampliam a percepção sobre a linguagem e, em consequência, suas ideias sobre o mundo em sua volta. Todavia, para que isso ocorra, se faz necessário um trabalho sistemático de interação com os diferentes textos que produzimos. Neste âmbito que estão situadas as investigações icônicas para as práticas de leitura.

Em conformidade com a Semiótica de inspiração nos estudos de Peirce (1839-1914), se formula a Teoria da Iconicidade Verbal (SIMÕES, 2007-2009). Essa construção teórica se propõe a orientar a leitura e também a produção de textos, baseando-se nas qualidades e relações sígnicas, a partir da possibilidade em identificar ícones e índices (função semiótica) na superfície dos textos.

Uma vez compreendidas as funções semióticas, os sujeitos estarão preparados para enfrentar leituras de textos simples e complexos, a partir daí poderão enfrentar os sinais que thes dão condições de entender a mensagem do texto.

A Teoria da Iconicidade verbal vem suprir a necessidade crescente de uma base teórica que observasse o signo em sua materialidade sonora e visual. $O$ interesse pela materialidade do signo surge ao se considerar a mediação durante a interação comunicativa. Seja no nível da oralidade, seja no nível da escrita, a materialidade do signo se evidencia. Nestes termos, acredita-se na premissa de que qualquer signo é criado a partir da imagem mental sobre algo. Essa primeira imagem é um ícone. Ela se torna conhecida por meio de sua representação de um ícone de segunda, ou hipoícone, o qual tenta re(a)presentar o objeto pensado a partir de um sinal material ou gráfico.

Disso é possível deduzir que temos por premissa que o ícone é fonte primária do signo. A prova disso é encontrada na origem da comunicação humana, já que as primeiras linguagens humanas se constituíram a partir das imagens. 
Segundo SIMÕES (1994i - 2009), "O iconismo da imagem se assenta em relações de analogia ou similaridade com seu referente (ideia-objeto representada)." Conforme a Semiótica visual, a imagem é uma manifestação auto-suficiente, une um texto porque comunica uma mensagem (SIMÕES, id.).

Existem diversas posições teóricas sobre iconicidade. Ocupamonos da iconicidade do signo verbal, na qual se destaca a iconicidade diagramática. Diferentemente do construto de Saussure, o enfoque paradigmático e sintagmático no plano semiótico observa as relações simbólicas possíveis extraídas da superfície textual, as quais servem de indutores para a interpretação.

Cumpre esclarecer que, nessa perspectiva, não são consideradas as relações in praesentia o in absentia - tão relevantes para o estudioso genebrino. Do ponto de vista semiótico aqui adotado, os signos produzem sua semiose a partir da relação imediata emergente de sua participação nos textos. Não se devem desprezar as inferências, ilações, implicaturas etc., mas a produção do signo interpretador do signo interpretado nasce da contextualização do signo, já que tudo pode ser signo de tudo (cf. SIMÕES, 2007, p.42).

Ademais, signo é tudo o que possa ser conhecido, tudo o que possa ser reconhecido. Todavia, para que um signo potencial possa funcionar como signo, deve estar relacionado a um objeto, deve ser interpretado e produzir um interpretante na mente do sujeito implicado. Este processo interpretativo é denominado semiose. E a iconicidade focalizada neste artigo é a potencialidade de materializar nas mentes interpretadoras signos-referência, os quais deflagrem o processo interpretativo independentemente do código em uso (SIMÕES ibidem).

Assim sendo, o edificio da Teoria da Iconicidade Verbal tem por premissas:

1. O signo verbal é uma imagem. (sonora o visual); 
2. A seleção e a combinação produzem a iconicidade textual no nível diagramático;

3. O projeto comunicativo se baseia na verossimilhança e visa à eficácia textual;

4. O texto deve ser analisado em seus atributos plásticos;

\section{2- ACTANTES, ENUNCIADOS E LEITURA}

Nos termos apontados por Greimas (1979, p.11), um enunciado omitido nas manifestações textuais assinala a presença de enunciados subjacentes que aparecem como uma representação sintático-semântica e que expressa um nível de estrutura profunda. As estruturas de superfície manifestam textos ocorrenciais. Assim, o enunciado elementar é concebido como função que se relaciona por relações paradigmáticas.

No nível do esquema sintático, compete às unidades paradigmáticas organizarem a narrativa. Para Greimas (Op cit, p.18 )"é somente o reconhecimento das projeções paradigmáticas que permite falar da existência das estruturas narrativas". Ao reconhecer as relações pragmáticas, igualmente são reconhecidas a as sintagmáticas que também podem desempenhar o papel de eixo condutor das emanações por onde se articulam os elementos de expressão do sentido.

Nas dimensões do espaço destinado ao enunciado de base é onde encontramos o sujeito com um actante definido pela função na qual se inscreve. Nas relações sintagmáticas (presentes na estrutura narrativa) repousa um sentido, um agente motivador. Situa-se nesse ponto o que Greimas chamou de conceito operatório e que evidencia o esquema narrativo, locus de articulação da atividade humana a qual erige em significação (1979, p.14).

Desta forma, implícita ao sentido produzido nas comunicações está a sintaxe pela qual circulam actantes de um discurso, no 
contexto da enunciação. A memória dos actantes aparece nos discursos através do encadeamento de certos elementos que na enunciação expressam as marcas de espaço, tempo e dos sujeitos que se situam na enunciação. Cada discurso contém determinantes para a sua leitura, diretamente implicados aos seus estatutos discursivos e ao conjunto de signos através dos quais ganham materialidade.

\section{3 - A LEITURA E O LEITOR}

Ao trazermos a este contexto os postulados da Semiótica narrativa e discursiva, o fazemos por entender que, ao lidarmos com o leitor contemporâneo nos cenários das práticas pedagógicas, o que se observa na maioria dos casos, principalmente nos estudantes que iniciam a graduação - e até mesmo nos já graduados - são relações de leitura nas quais o sujeito leitor posiciona -se como único. Neste caso, o diálogo entre sujeito autor e sujeito leitor deixa de existir , ou se torna frágil.

Necessário se faz termos em mente que a negação do outro decorre das dificuldades em compreender que ler implica em desmanchar o percurso elaborado pelo outro, retirando o conteúdo, o conjunto de idéias emanadas pelo texto. Os índices oficiais sobre o desempenho de nossos alunos, assinalam o resultado de tal prática. Por este anglo, a experiência docente nos revela que a leitura se realiza por transferência, por um desejo de que o outro tenha querido dizer algo que se ajusta às vivências do leitor.

Inegável é o fato de que somos frutos de nossas experiências e que nossa visão de mundo se origina do mundo culturalmente compartilhado. Nossa reflexão caminha para as questões que se manifestam no cotidiano com a leitura, na percepção de papel desempenhado pelo leitor frente ao texto acadêmico. Nesta 
modalidade textual, o sujeito -leitor é inserido nos mecanismos de construção e comunicação do conhecimento.

O sujeito - leitor fica diante, sobretudo, de um universo lexical e dos procedimentos normativos do grupo comunitário profissional e científico ao qual pertence o discurso produzido, em um contexto específico. Trata-se, em termos gerais, de reconhecermos diferenças motivadoras que circundam a elaboração de um texto acadêmico e a necessidade de haver uma preparação para a realização da leitura. De maneira geral, o sujeito-leitor, no caso dos graduandos, não dispõe de ferramentas que o auxiliem a penetrar na leitura.

Em decorrência, em termos exemplificativos, reportamo-nos aos textos de TCC (Trabalhos de Conclusão de Curso), nos quais é comum a presença de produção textual cuja intencionalidade seja apresentar as idéias de determinados autores ou teorias. Muitas vezes, o que temos é uma distância acentuada entre os conceitos, ou proposições de pesquisadores, e o que o sujeito - leitor - aluno trás em seu texto.

O fenômeno identificado mostra um leitor que lê a si próprio no outro. Narra uma intencionalidade discursiva atribuída a determinado autor, fato muita vezes cobrado em bancas examinadoras. A problemática ganha destaque na medida em que, ao entrarmos nas dimensões do texto científico, saímos do imaginário subjetivo, alimentado pela poética, para atingirmos a literatura científica e seu estatuto: comunicação da produção do conhecimento.

A aplicação de elementos da teoria greimasiana como ferramenta na formulação de um método para as práticas de leitura da literatura científico- acadêmica tem se revelado eficaz. Dela destacamos alguns pontos: a concepção da narração sempre presente nos níveis mais profundos; os papéis actanciais e o percurso em torno do objeto- valor.

Em primeiro plano, ao se ter à compreensão segunda a qual toda produção textual apresenta, independentemente da forma 
manifestada, tem em sua estrutura profunda a intencionalidade narrativa, permite a formulação de uma primeira base conceitual sobre a literatura acadêmico-científica e um instrumental para o sujeito -leitor: o autor tem como intencionalidade contar 0 pensamento dele em torno de determinada temática, narrar a idéia e como chegou a ela e em quais pontos a fundamenta. Neste caso, o sujeito-leitor deve identificar o caminho elaborado pelo sujeito-autor.

Com relação aos papéis actanciais, temos aí um ponto fundamental para a leitura do texto científico: a separação entre o sujeito-leitor e o sujeito - escritor. Separadas essas relações actanciais, opera-se um fato importante que é a identificação dos sujeitos com os quais o escritor dialoga para a fundamentação de suas idéias. Quais os papéis de cada um no contexto do discurso elaborado? Em relação ás idéias, cumprem o papel de adjuvantes ou oponentes?

Como define Greimas, no clássico Prefácio à obra de Courtés:

o percurso narrativo de um destinador, possa aparecer não apenas como o lugar de exercício do poder estabelecido, mas também como aquele que em que esboçam os esquemas de manipulação e se elaboram ações narrativas auxiliares visando levar os sujeitos a realizarem um determinado fazer desejado ( COURTES, 1979,p.33 )

Nos termos da literatura acadêmica, o autor é o destinador cujo objeto valor reside na própria comunicação do conhecimento. Para tal realiza programa narrativo constituído ações reflexivas e práticas que nortearam o resultado final. Do tema à sustentação de hipóteses, portanto, o destinador busca a sedução baseada em mecanismos operacionais característicos do universo de discurso acadêmico. Seus pares, referências e fontes de pesquisa, ajudam a configurar a lógica da sedução.

A conjunção com o objeto de desejo está presente na medida em que se realiza a leitura, a decomposição do percurso elaborado 
pelo destinador. Compete ao leitor, em seu papel a de sujeito, caminhar pelo percurso do outro, do autor e identificar cada as narrativas auxiliares trazidas no texto que dão forma as idéias do outro, do destinador. Em posse do percurso realizado pelo outro pode expressar seu saber e conhecimento e trazer o resultado desta leitura para a elaboração de outro discurso, outro texto.

\section{CONSIDERAÇÕES FINAIS}

A preocupação com as práticas pedagógicas voltadas à leitura nos diferentes níveis de ensino está presente em vários seguimentos de pesquisa. Muitos são os resultados de avaliações que ganham espaços em diferentes veículos midiáticos revelando resultados aquém do que se espera do estudo em habilidades de leitura.A Sociedade do Conhecimento precisa de mais seres envolvidos no sistema social e com o conhecimento. Na chamada massificação do ensino superior, esse destinatário é acentuadamente marcado por todos os fatores.

Estamos falando da comunicação do conhecimento: da leitura difícil ou da leitura fácil. Reside nesse ponto a problemática: como formar indivíduos socialmente responsáveis, capazes de identificar problemas, gerar soluções e comunicá-las em um universo do saber/ conhecimento enquanto objeto de consumo? $\mathrm{Na}$ sociedade para a qual ver se confunde com saber? Longe de esgotarmos a temática, apresentamos um caminho que trilhamos em busca de instrumentais para o trabalho com a leitura e o sujeito leitor.

A Semiótica, seja qual for a vertente, oferece base conceitual para a realização de leituras das diferentes linguagens. Neste sentido, ter como subsídio um diálogo entre teorias da Semiótica e da Linguística, com vistas a orientar a análise e a interpretação das produções discursivas - materializadas em textos na sociedade e nas salas de aula.nos diferentes níveis de ensino tem revelado resultados 
edificantes,seja qual for a modalidade textual. Levando-se que as dinâmicas em aulas de linguagem têm por objetivo a eficácia na comunicação,implícito está a necessidade de dotar o sujeito de um saber específico em relação à modalidade da linguagem na qual se manifeste o objeto da leitura.

Por último, o nível de conhecimento remete ao nível de apreensão realizado pelo sujeito. A partir das bases conceituais de Peirce, nasceu a Teoria da Iconicidade Verbal, que vem subsidiando as aulas de gramática e estilística; no mesmo caminho, a utilização de recursos inspirados na teoria de Greimas, temos desenvolvemos estudos dos processos de enunciação, sujeito e leitura que dão suporte à leitura e a produção de textos acadêmicos. Além de otimizar 0 ensino dos conteúdos linguístico-gramaticais indispensáveis ao adequado desempenho verbal nas instâncias públicas (a norma culta), estamos conseguindo formar sujeitos leitores plurais.

\section{REFERÊNCIAS :}

BAKHTIN, M. Marxismo e filosofia da linguagem. 9a ed. São Paulo: Hucitec, 1999.

COURTÉS, J. Introdução à Semiótica Narrativa e Discursiva. Coimbra: Almedina, 1979.

MELO. E. "Leitura, Literatura Científica e as Parábolas do Conhecimento". Caderno Seminal,vol.9, no 9 (jan/jun-2008). Rio de Janeiro, Dialogarts, 2008.2 Disponivel em <http://www.dialogarts.uerj.br/arquivos/seminal09.pdf>

.PRADOS, R.M.,GARCIA W. Linguagens, tecnologias,

Culturas: discursos contemporâneos. São Paulo: Editora Factach ,2008.

SIMÕES, Darcilia. Iconicidade e verossimilhança. Rio de Janeiro: Dialogarts. 2007. Disponível em http://www.dialogarts.uerj.br - Iconicidade Verbal: Teoria e Prática. Rio de Janeiro: Dialogarts, 2009. Disponível em: http://www.dialogarts.uerj.br 
TODOROV\&DUCROT. Dicionário das. C. da Linguagem. Lisboa: Publicações Dom Quixote, 1982. 